\title{
ELIMINAÇÃO DE PROCESSO DE LIXAMENTO EM EIXOS DE TRANSMISSÃO UTILIZANDO REBOLO DE CBN VITRIFICADO
}

\author{
Paulo Sérgio Martins, Roney Gonçalves, Daniel Bastos de Rezende, Daniel Miranda, Flavio \\ Goulart
}

Fiat Chrysler Latam

\begin{abstract}
E-mail: paulo.martins@fiat.com.br, roney.goncalves.fiat.com.br, daniel.rezende@fiat.com.br, Flavio.Goulart@ fiat.com.br, Daniel.Miranda@fiat.com.br
\end{abstract}

\section{RESUMO}

O processo de retificação vem apresentando grandes avanços na tecnologia de materiais utilizados na fabricação de rebolos. Liga de CBN vitrificado vem crescendo na aplicação de processo de retificação em eixos para transmissão. A substituição de abrasivos convencionais por superabrasivos (Rebolos), com vistas à otimização do processo, merece um estudo bem aprofundado, pois são muitos os fatores que influenciam no processo de retificação. Tolerâncias estreitas de forma geométrica e de posição, a grande sensibilidade do material em apresentar defeitos de origem térmica (microtrincas) e a necessidade do não aparecimento de rebarbas são os aspectos que mais dificultavam a introdução do novo tipo de abrasivo. A busca por redução de tempo e melhores superfícies tribológicas, vem impulsionando o crescimento da aplicação de rebolos de CBN nos processos de retificação de peças automotivas. Redução de tempo ciclo em um processo de retificação é fundamental para garantir a competitividade e um menor custo do processo, mas deve se levar em conta a qualidade da superfície gerada pela ferramenta. No presente estudo propõe-se avaliar a superfície $R_{a}$ após aplicação do processo de retificação cilíndrica de eixos 19MNCR5 G temperado e revenido com $62 \mathrm{HRc}$ ), para certificar a possibilidade de eliminação do processo lixamento na utilização de rebolos de $\mathrm{CBN}$ vitrificado.

\section{INTRODUÇÃO}

Processo de retificação é conhecido como um dos mais complexos de usinagem, devido ao grande número de variáveis envolvidas. Na retificação, muitas dessas variáveis assumem comportamentos diferentes dos exibidos na retificação convencional. Dessa forma, o processo ainda é pouco conhecido teoricamente e, por esta razão, tem sido um assunto de grande interesse no meio científico. Geralmente, este tipo de usinagem é posterior ao torneamento e ao fresamento, para um melhor acabamento da superfície. O sobre-metal deixado para o processo de retificação é da ordem de 0,2 a $0,5 \mathrm{~mm}$, porque a retificadora e uma máquina de custo elevado e seu emprego encarece o produto. A retificação é um processo de usinagem por abrasão, retificar significa corrigir irregularidades nas superfícies das peças por tratamento térmico.

O desenvolvimento de novos materiais para ferramenta e de máquinas tem propiciado também a usinagem desses tipos de peça nas operações de torneamento e fresamento, mas em situações que não sejam exigidas classes de tolerâncias dimensionais abaixo de IT5. Para essas situações, as operações de retificação ainda detêm certa supremacia, já que também ocorreram fortes desenvolvimentos nessa área. Isso se refere principalmente às novas 
máquinas retificadoras, com os recursos do $\mathrm{CNC}$, mancais e guias hidrostáticas, motores que possibilitam altíssimas velocidades de corte e também melhorias nos rebolos, como a utilização de superabrasivos, granulometrias extremamente reduzidas e o desenvolvimento de ligantes especiais para essas novas condições [1].

Diversos fatores influenciam na escolha do fluido, como viscosidade, características técnicas, custo etc., e, mesmo após sua escolha, ainda existem outras considerações que devem ser feitas para seu melhor aproveitamento. Entre as características citadas, destacam-se a geometria do bocal pelo qual o fluido será introduzido na operação, a intensidade de pressão e a vazão na saída do bocal, a posição mais acertada para a colocação do bocal, sendo todas de substancial importância para a melhoria da qualidade final da peça.

A retificação era um dos processos preferidos na usinagem de materiais duros ou endurecidos Os fluidos de corte são utilizados como um agente externo às condições de usinagem, com a função de otimizar o processo através do aumento da ação lubrificante e refrigerante na região de corte. Porém, a eficiência de um fluido de corte dependerá da vazão, direção e velocidade de sua aplicação. Há no mercado uma grande diversidade de óleos e fluidos de corte para os diferentes processos de usinagem que desejam usá-los.

Até o surgimento do CBN, a escolha do abrasivo recomendado para retificação de aços endurecidos recaía quase que exclusivamente sobre o coríndon (óxido de alumínio). Comparando-se as características desses rebolos, tem-se nos de coríndon, com ligante vitrificado, velocidades de corte máximas de $60 \mathrm{~m} / \mathrm{s}$, enquanto que com CBN e o mesmo ligante já são usadas velocidades de $120 \mathrm{~m} / \mathrm{s}$. Em rebolos com abrasivos convencionais, as profundidades de corte utilizadas situam-se na ordem de décimos de milímetro, já com rebolos de CBN são usuais as aplicações de corte em cheio, como na abertura de canais para brocas helicoidais, retirando-se vários milímetros por passe. A possibilidade de aumento nas velocidades de avanço com rebolos de CBN também é uma realidade.

\section{INFORMAÇÕES GERAIS}

O CBN é um material sintético, obtido através da transformação do nitreto de boro hexagonal, mediante elevadas pressões e temperaturas. Com altíssima dureza (K100 $=4700)$, independente da orientação dos cristais, apresenta vantagens na aplicação quando comparado ao diamante, devido à possibilidade de usinagem de ferrosos. Isso porque, apesar da extrema dureza do diamante $(\mathrm{K} 100=7000)$, o seu emprego na usinagem de aços, principalmente hipoeutéticos, é dificultada pela tendência do carbono do diamante a se difundir no ferro, sob condições de pressão e temperatura usuais de usinagem.

Além disso, comparado ao diamante, o $\mathrm{CBN}$ apresenta uma resistência elevada à temperatura. Enquanto que em diamantes a grafitização inicia a partir de $900{ }^{\circ} \mathrm{C}$, o nitreto de boro cúbico, à pressão atmosférica, apresenta estabilidade até $2000{ }^{\circ} \mathrm{C}$. Paralelamente a isso, segundo Bertalan (1997), a queda da dureza do diamante com o aumento de temperatura é acentuada a partir de $500{ }^{\circ} \mathrm{C} \mathrm{e} \mathrm{em} 800{ }^{\circ} \mathrm{C}$ ela é inferior à do $\mathrm{CBN}$ na mesma temperatura.

As duas considerações mais importantes quando se trabalha com rebolos são a refrigeração e a lubrificação. Uma refrigeração adequada possibilita maior vida útil ao rebolo. Já a lubrificação permite obter uma produtividade adequada à aplicação em que ele está sendo utilizado [2]. Um fluido de corte não deve apenas promover uma boa refrigeração da peça por convecção. Ele deve favorecer a predominância dos mecanismos de corte, em vez da deformação plástica sem a remoção de material (plowing). Assim, a energia específica total de retificação gerada no processo de usinagem é diminuída [3].

A retificação com superabrasivos, devido às altas taxas de remoção de material e velocidades de corte possíveis, requer normalmente a aplicação de fluidos de corte, seja pela necessidade de redução da temperatura de corte, como também para limpeza de cavacos nos 
poros do rebolo. Em situações de retificação a seco são empregados ligantes especiais e a operação é realizada com o uso de passes mais suaves e reduções de aproximadamente $30 \%$ na velocidade de corte. Os fluidos normalmente utilizados são emulsões de óleos sintéticos (concentrações de 2 a $5 \%$ ) e óleos minerais aditivados [4].

Uma outra razão para o menor desgaste é devido ao efeito térmico. A condutibilidade térmica do CBN é dezoito vezes maior que a do coríndon e superior à do ferro, de modo que uma parte do calor gerado pelo processo é transmitida aos grãos [5]. Como o grão abrasivo na retificação passa uma parte extremamente grande de tempo fora do contato com a peça e pela maior condutibilidade térmica do $\mathrm{CBN}$, é facilitada a ação do fluido de corte e do ar na redução do calor gerado no corte. Isso faz o grão retornar à temperatura ambiente e recuperar a sua capacidade de absorver calor no contato seguinte [6]. Como na retificação com CBN o grau de afiação do abrasivo é mantido por tempos mais longos e a temperatura resultante na peça é muito inferior a da retificação com coríndon para as mesmas condições de corte, a dureza na peça dificilmente se altera e as deformações térmicas são sensivelmente menores, o que reduz a ocorrência de tensões residuais de tração que tendem a provocar trincas.

\section{PROCEDIMENTO EXPERIMENTAL}

Análise comparativa dos parâmetros tribológicos medidos na região da sede de vedação e sede do rolamento agulha dos eixos primários, aplicação transmissões C510 e C513 retificados com rebolo de CBN (Nitreto Cubico de Boro) e a eliminação do processo de lixamento nas mesmas regiões, com os valores referência de $R_{t}$ e $R_{z}$ indicados pelos fornecedores de retentor. Foram medidas cinco amostras, nas quais foram controlados os seguintes parâmetros: $\mathrm{R}_{\mathrm{a}}, \mathrm{R}_{\mathrm{t}}, \mathrm{R}_{\mathrm{z}} \mathrm{e} \mathrm{R}_{\mathrm{sm}}$. Figura 1 mostra os pontos controlados (Valores de $\mathrm{R}_{\mathrm{a}}$ $0,20 \sim 0,40$.)

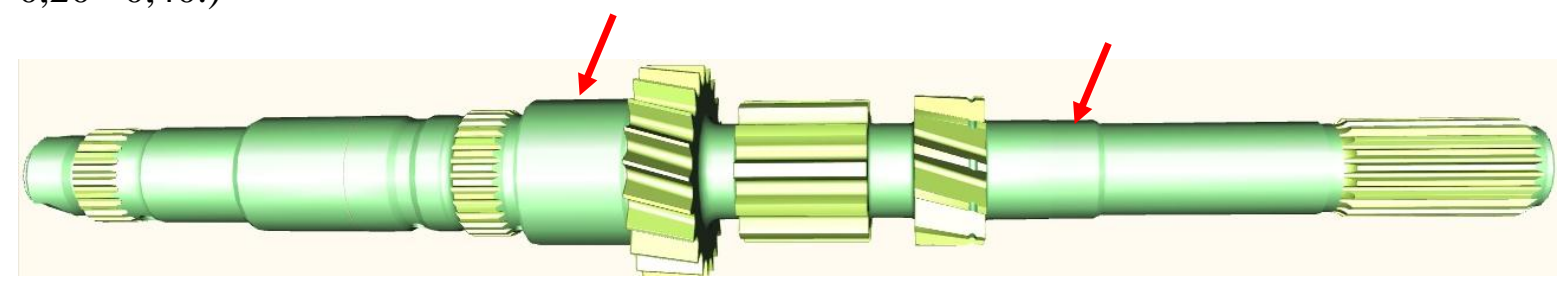

Figura 1: Eixo primário pontos de controle sede rolamento (Fonte: autor).

As cinco peças foram retificas em máquina Tacchella Prossflex2HS145CBN- potência $90 \mathrm{KW}$ utilizando parâmetros de corte $\left(\mathrm{V}_{\mathrm{C}} 120 \mathrm{~m} / \mathrm{min}\right)$ e rebolos em $\mathrm{CBN}$ vitrificado. $\mathrm{O}$ equipamento utilizado na medição da superfície foi um rugosímentro da marca Mitutoyo SJ-210 - $178-561-02 \mathrm{~A}$.

\section{RESULTADOS}

Tabela 1 mostra o comportamento da superfície usinada. Percebe-se que comportamento dos pontos medidos manteve-se próximo dos valores especificados no produto. 
Tabela 1: Valores medidos na superfície de apoio do rolamento de agulha.

\begin{tabular}{|c|c|c|c|c|c|c|}
\hline \multicolumn{2}{|c|}{$\begin{array}{l}\text { Parâmetros } \\
\text { Ponto Medição }\end{array}$} & 1 & 2 & 3 & 4 & 5 \\
\hline \multirow{4}{*}{ 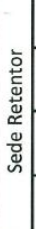 } & Ra 0,2 a 0,4 & 0,230 a 0,316 & 0,254 a 0,337 & 0,260 a 0,363 & 0,252 a 0,300 & 0,280 a 0,346 \\
\hline & Rt & 1,860 a 2,247 & 2,171 a 2,680 & 2,398 a 2,855 & 2,441 a 2,691 & 2,421 a 3,313 \\
\hline & $\mathrm{Rz}$ & 1,621 a 2,276 & 1,795 a 2,372 & 2,159 a 2,480 & 1,836 a 2,251 & 2,071 a 2,668 \\
\hline & $\mathrm{RSm}$ & 44,74 a 55,90 & 50,68 a 60,19 & 47,62 a 62,18 & 51,28 a 54,24 & 48,65 a 50,52 \\
\hline \multirow{4}{*}{ 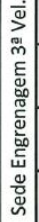 } & Ra 0,4 & 0,239 & 0,249 & 0,242 & 0,227 & 0,255 \\
\hline & Rt & 2,110 & 2,549 & 2,611 & 2,306 & 2,870 \\
\hline & $\mathrm{Rz}$ & 1,739 & 2,028 & 2,044 & 2,014 & 2,348 \\
\hline & $\mathrm{RSm}$ & 45,89 & 52,76 & 56,87 & 55,56 & 53,64 \\
\hline
\end{tabular}

Obs: Ver graficos anexo 1 a 15.

De acordo com a Figura 2, observou-se que dispersão da rugosidade Ra manteve-se centrada com as condições previstas de parâmetros de corte. As peças avaliadas foram montadas na transmissão e testes de durabilidade foram realizados. $\mathrm{O}$ comportamento durante os teste foi similar ao comparado com processo antigo, utilizando rebolos cerâmicos e posteriormente lixamento. Alteração da topográfica não interferiu no funcionamento mecânico da transmissão.

Taylor Hobson

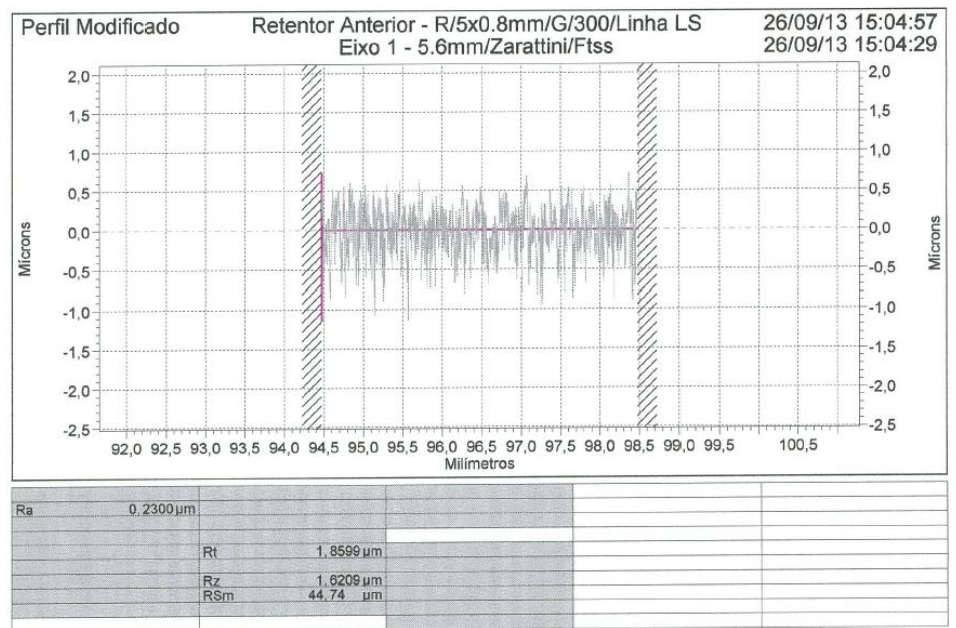

Figura 2: Avaliação da superfície $\mathrm{R}_{\mathrm{a}}$. 


\section{CONCLUSÃO}

A aplicação de rebolos de CBN vitrificado na retificação do eixo primário obteve bons resultados comparados ao processo utilizando retificação com rebolos cerâmicos. As superfícies topográficas $\mathrm{R}_{\mathrm{a}}$ mantiveram-se bem estáveis durante o processo de análise. Com aplicação de rebolos de CBN, foi possível eliminar o processo de lixamento, consequentemente, reduzindo pontos de aplicação no processo produtivos.

\section{REFERÊNCIAS}

[1] Diniz, A.E., Marcondes, F. C. \& Coppini, N. L., 1999, Tecnologia da Usinagem dos Materiais, MM Editora, vol. 1, São Paulo, SP, pp. 223-242.

[2] Mariani, G. \& Trebing, C. Synthetic coolants cut it in superabrasive grinding. Livonia, MI: Technical Services, Pills Bury Div., Novamax Technologies Inc., 1998, pp. 3-7.

[3] Maris, M. \& Snoyes, R. Heat affected zone in grinding operations. Proceedings of the 14th International Machining Tool Design and Research Conference, pp. 659-669, 1974.

[4] Winter do Brasil, 1997, Rebolos, Catálogo de Fabricante, Jundiaí, SP.

[5]Bertalan, C., 1997, Retificação com Rebolos de Nitreto de Boro Cúbico em MáquinasFerramenta Convencionais, Dissertação de Mestrado em Engenharia Mecânica, Universidade Federal de Santa Catarina, Florianópolis, SC.

[6] Basto, F. S., 1999, Retificação Cilíndrica Externa para Diferentes Condicionamentos do Rebolo de Nitreto de Boro Cúbico, Dissertação de Mestrado em Engenharia Mecânica, Universidade Federal de Santa Catarina, Florianópolis, SC. 